
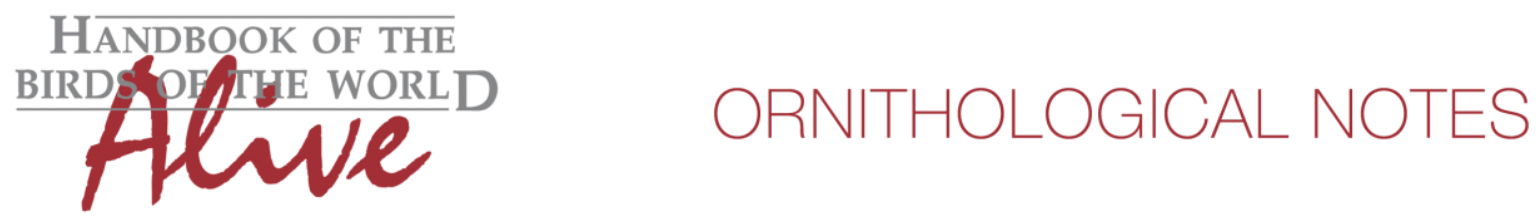

\title{
Notes on the vocalizations of Golden-crowned Flycatcher (Myiodynastes chrysocephalus) and Golden-bellied Flycatcher (Myiodynastes hemichrysus).
}

Peter Boesman

In the following we briefly analyze and compare voice of the different races of Golden-crowned Flycatcher (Myiodynastes chrysocephalus) and Golden-bellied Flycatcher (Myiodynastes hemichrysus). We also try to quantify the extent of any vocal differences using the criteria proposed by Tobias et al. (2010), as a support for taxonomic review. We have made use of sound recordings available on-line from Xeno Canto $(\mathrm{XC})$ and Macaulay Library (ML).

Both species have a dawn-song and a commonly heard loud day-time song. We will compare both vocalizations for the 4 taxa. (There are also interaction calls etc. which we are discarding here).

Myiodynastes hemichrysus

dawn-song: a repeated "kwee!-tee-t-tu" ( $n=1)$

min. freq. $\quad 2140 \mathrm{~Hz}$

max. freq. $\quad 5600 \mathrm{~Hz}$

total length $\quad 0.39 \mathrm{~s}$

length 1st note $\quad 0.13 \mathrm{~s}$

day-time song: a repeated loud strident "skeeew!" ( $n=6)$

min. freq. $\quad 1200-1550 \mathrm{~Hz}$

max. freq. $\quad 5350-5830 \mathrm{~Hz}$

total length $\quad 0.18-0.25 \mathrm{~s}$

M. c. minor

dawn-song: a repeated "kwee!-tee-tu" or "kwee!-tee-tu-ti-lu" ( $n=3)$

min. freq. $\quad 1380-1590 \mathrm{~Hz}$

max. freq. $\quad 5290-5740 \mathrm{~Hz}$

total length $\quad 0.32-0.43 \mathrm{~s}$

length 1st note $\quad 0.12-0.14 \mathrm{~s}$

day-time song: a loud strident "skeeeuw!" ( $n=6)$

min. freq. $\quad 1030-1450 \mathrm{~Hz}$

max. freq. $\quad 5000-5550 \mathrm{~Hz}$

total length $\quad 0.15-0.29 \mathrm{~s}$

M. c. cinerascens

dawn-song: a repeated "kwee!-tee-tu" ( $n=2)$

min. freq. $\quad 1300-1320 \mathrm{~Hz}$

max. freq. $\quad 5030-5120 \mathrm{~Hz}$

total length $\quad 0.37-0.39 \mathrm{~s}$

length 1st note $\quad 0.15-0.16 \mathrm{~s}$

day-time song: a loud strident "skeeew!" or "skeeeuuw!" ( $n=6)$

min. freq. $\quad 1060-1400 \mathrm{~Hz}$

max. freq. $\quad 4540-6340 \mathrm{~Hz}$

total length $\quad 0.17-0.28 \mathrm{~s}$ 


\section{HANDBOOK OF THE BIRDSPFGE WORLD}

\section{ORNITHOLOGICAL NOTES}
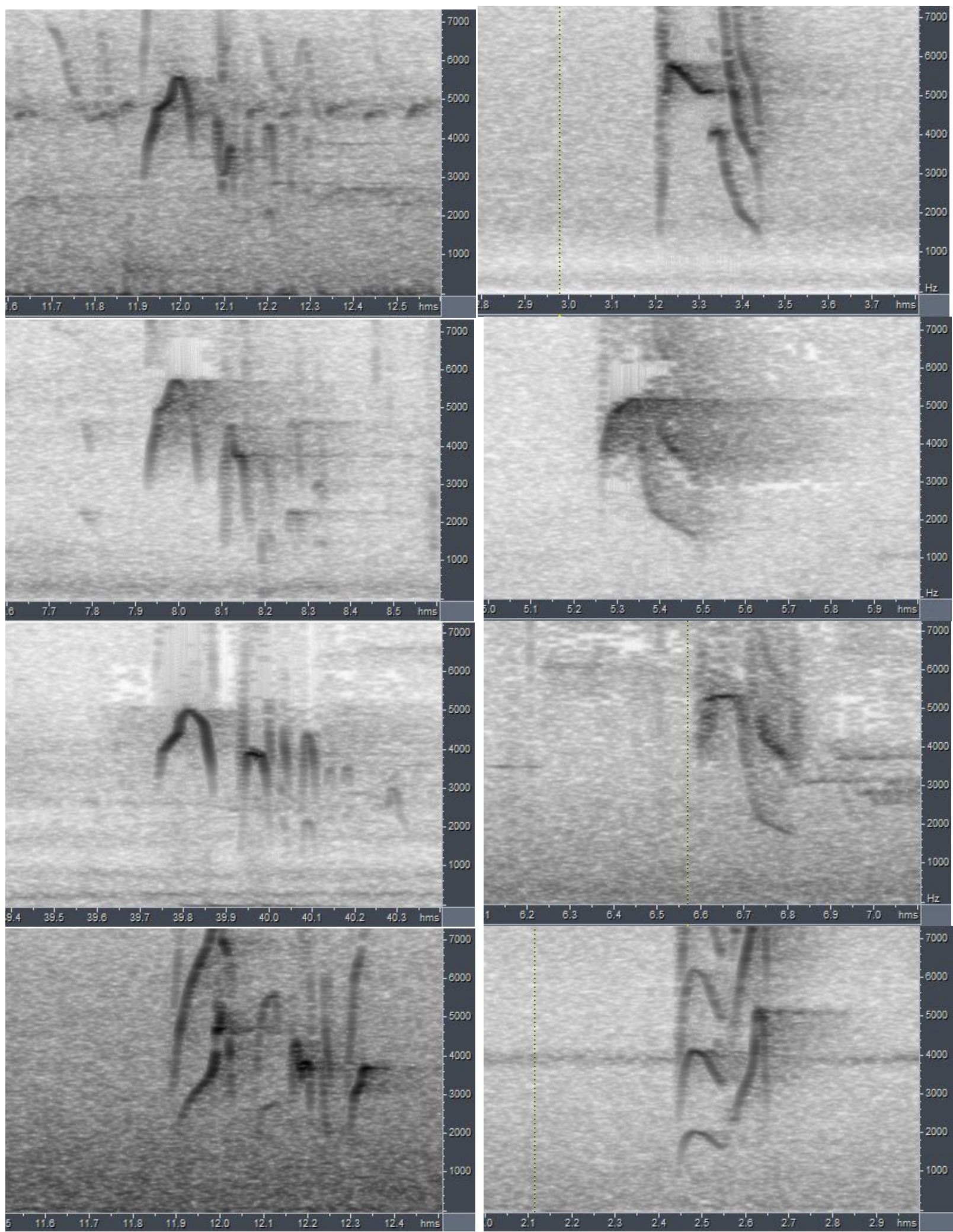

Figure 1: from top to bottom: dawn song (left) and day-time song (right) of M. hemichrysus, M.c.minor, M.c.cinerascens and M. c. chrysocephalus 

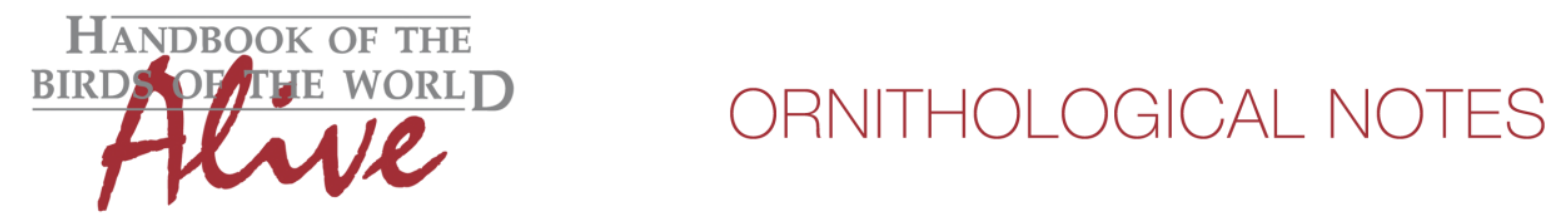

\section{M. c. chrysocephalus}

dawn-song: a repeated "kwee!-tlu-tee" $(n=2)$

min. freq. $1950-2050 \mathrm{~Hz}$

max. freq. $\quad 5220-5300 \mathrm{~Hz}$

total length $\quad 0.42-0.46 \mathrm{~Hz}$

length 1st note $\quad 0.12-0.13 \mathrm{~s}$

day-time song: a loud strident "ku-weet!" or "ku-weet!.. weet!" (weet! sharply rising and much higher-pitched than first note) $(n=8)$

min. freq. $\quad 1150-1380 \mathrm{~Hz}$

max. freq. $\quad 4000-5300 \mathrm{~Hz}$

total length $\quad 0.22-0.66 \mathrm{~s}$

\# of notes $2-3$

It is clear from the above analysis that the only race which has clear vocal differences is M. c. chrysocephalus.

Voice of Myiodynastes hemichrysus is about identical to M.c. minor and M.c. cinerascens.

We would need a large number of samples to prove any consistent difference, but in any case it would be very small. (Possibly the note shape is slightly different, with $M$. hemichrysus having a little notch at the right side of the day-time song). Difference score for these taxa is thus 0 (or possibly 1).

Difference with chrysocephalus at the other hand is quite noticeable:

Day-time song has 2 (or 3) distinct notes (score 3) with very different note shape (score 1) and slightly longer overall length (score 1 ).

Dawn song ends with a fairly emphasized rising note (unlike all other races which end in subdued notes) (score 2 ) and note shape of first note different (score 1 ).

The fact that both dawn song and day-time song are clearly different makes this case even more convincing. When applying Tobias criteria, this would lead to a total vocal score of about 5.

This note was finalized on 13th July 2015 , using sound recordings available on-line at that moment. We would like to thank in particular the many sound recordists who placed their recordings for this species on XC and ML.

\section{References}

Tobias, J.A., Seddon, N., Spottiswoode, C.N., Pilgrim, J.D., Fishpool, L.D.C. \& Collar, N.J. (2010). Quantitative criteria for species delimitation. Ibis 152(4): 724-746.

\section{Recommended citation}

Boesman, P. (2016). Notes on the vocalizations of Golden-crowned Flycatcher (Myiodynastes chrysocephalus) and Golden-bellied Flycatcher (Myiodynastes hemichrysus). HBW Alive Ornithological Note 141. In: Handbook of the Birds of the World Alive. Lynx Edicions, Barcelona. (retrieved from http://www.hbw.com/node/932065 on 10 August 2016). 